\title{
Country by country
}

\section{Anna Petherick investigates the nature of Chagas disease and how its management varies across Latin America.}

$\mathbf{T}$ he available data that describe Chagas disease's spread and impact are poor: they conceal assumptions, extrapolations and, in a few cases, alleged manipulations by government officials eager to minimize the apparent scale of the problem, and thus avoid pressure to deal with it (in the case of Mexico) or to overstate their performance at tackling the disease (Bolivia). The multinational Southern Cone, Andean, Central American and Amazon initiatives generate only recommendations for the $\sim 100$ Latin American provincial governments and 14,000 municipalities. These operate largely under their own steam. So the numbers given here merely sketch out the situation and there is often great variation within national borders.

\section{Venezuela - population 26.7 million}

Venezuela is a story of exemplary, sustained achievement that has been let slide in recent years. In 1961, it was one of the first countries to draw up a national campaign against Chagas disease. Before this, prevalence rates were $5-40 \%$ in the low Andes and open grasslands of the Orinoco basin, where sylvatic (forest-dwelling) Rhodnius prolixus is endemic. Nationally, prevalence among children aged $<10$ years was cut from $20 \%$ in 1960 to $0.8 \%$ in the late 1990s, and the size of the endemic area in Venezuela shrank by almost one-half. Since then, seroprevalence appears to have increased and dense populations of housedwelling $R$. prolixus have re-emerged ${ }^{1,2}$.

$R$. prolixus often reinvades from nearby palm trees after a house is sprayed. The successful four-decade-long campaign involved not only insecticide spraying but also a rural housing improvement project to lower the chance of vectorial transmission indoors. Half a million homes were constructed or modified. For example, roofs thatched with palm leaves, where $R$. prolixus often lays eggs, were replaced. Screening for Trypanosoma cruzi at blood banks became law in Venezuela in 1988. However, many researchers say that better surveillance is needed in the Venezuelan Amazon, where endemic areas might lie undiscovered.

\section{Brazil - population 186.4 million}

Vectorial transmission by Triatoma infestans was officially eliminated from Brazil in 2006 the result of a control programme that started in some areas in 1950 and became national in 1983. Other domestic vectors are rare but occur in patches. Overall, in 1970, there were 100,000 new cases transmitted by the insect vectors; in 2007 , there were 10 . However, the country still has 3 million infected individuals.

Demographic shift is partially responsible for the changes in vectorial transmission. Brazil has seen massive rural-to-urban migration over recent decades. At the same time, however, many have moved into the Brazilian Amazon. Consequentially, transmission by new, exotic vectors such as Rhodnius pictipes, Rhodnius robustus, Panstrongylus geniculatus and Panstrongylus lignarius has arisen. These sylvatic vectors often have high rates of T. cruzi infection and adults occasionally fly into houses near the forest.

Oral transmission in towns in and around the Amazon is an increasing concern. Between 2005 and 2007, 330 cases of orally acquired T. cruzi infection were recorded in the country, of which 272 came from the Amazon region. However, it was an outbreak in the rich, southern state of Santa Catarina in 2005 in which five people died that drew national attention to the issue. The problem seems to be getting worse: between 1968 and 2005, only 440 cases of oral transmission were identified ${ }^{3,4}$.

This rise is to some extent explained by improved screening. Researchers at the Instituto Evandro Chagas spearheaded the training of technicians to check routinely for T. cruzi infection with each blood smear test for malaria - so Chagas disease surveillance can piggyback off an existing federal screening programme.

\section{Mexico - population 107 million}

Mexico has been slow to get to grips with Chagas disease. Unlike most of the other countries in Latin America, it is not part of a transnational initiative, and has attended the meetings of the Central American Initiative only a few times.

There are several reasons for this. Prevalence is officially low (1.5\%) in Mexico, but the government has ducked the issue. There is no federal financing of Chagas disease control or monitoring, which leaves its 31 states to search for cash from their own budgets - and requires individuals to take it upon themselves to address the issue. Thirteen states have started to look into the disease, according to Janine Ramsey, who until recently was director of the

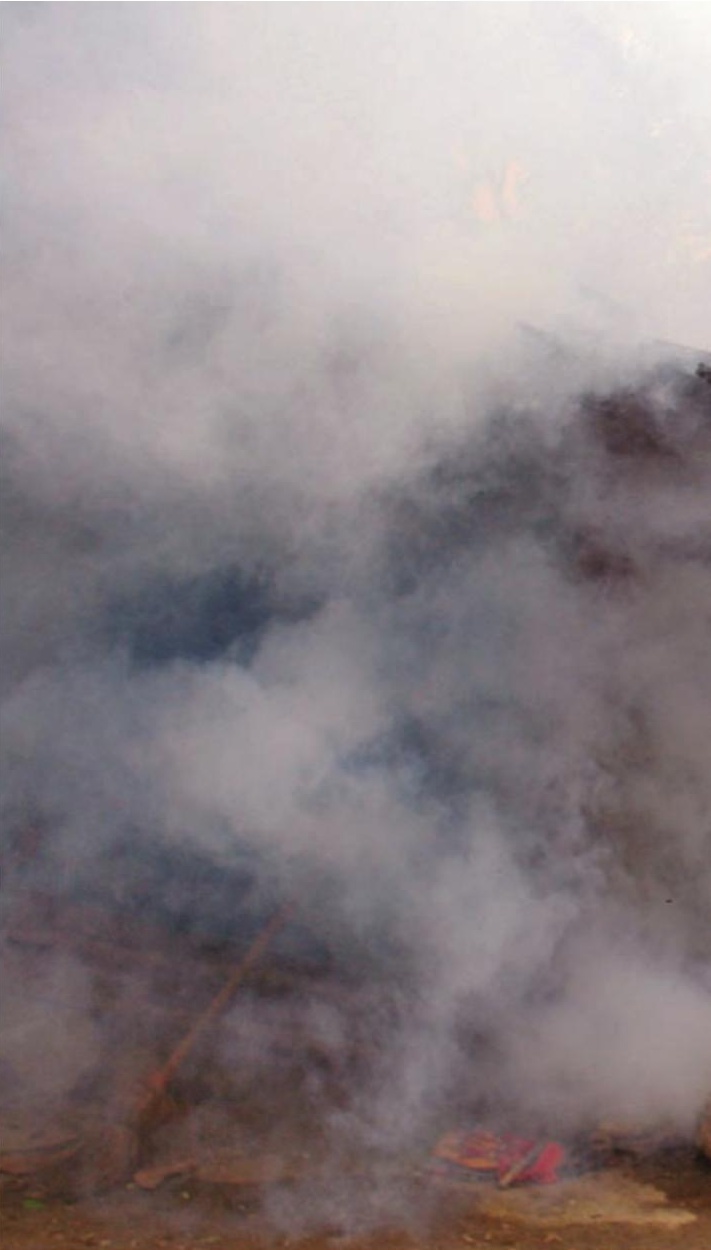

Regional Centre of Public Health Research in Tapachula, Chiapas. Ramsey estimates that 69,000 people are infected with T. cruzi each year in Mexico, only $\sim 30 \%$ of the national blood supply is properly screened and the true prevalence of infection is closer to $2 \%$.

Another historical hurdle came from public-health officials incorrectly arguing that DDT could kill T. cruzi vectors - and so the country needed only those spraying programmes already in place to fight malaria. This allowed the Chagas disease vectors to flourish, unchecked. Under the terms of the North American Free Trade Agreement (NAFTA) that Mexico signed in 1994, DDT has been banned in the country since 2006. This has been beneficial for controlling Chagas disease vectors, having encouraged the use of pyrethroids as a replacement. However, vector distribution is poorly documented.

\section{Bolivia - population 9.2 million}

Bolivia is Chagas disease's frontline. It has the biggest threat to fight: the disease is endemic across $60 \%$ of the country; it is T. infestans's ancestral home; and the country's Andean valleys harbour numerous sylvatic populations, from which re-infestation of homes can occur. In some parts of the country, every community member aged $>50$ years is infected. Bolivia is also one of the poorest countries in Latin America, with a large, rural population. 
